\title{
Article \\ A Novel Index to Detect Vegetation in Urban Areas Using UAV-Based Multispectral Images
}

\author{
Geunsang Lee ${ }^{1}\left(\mathbb{D}\right.$, Jeewook Hwang ${ }^{2, *}$ and Sangho Cho ${ }^{3, *}$ \\ 1 Department of Cadastre \& Civil Engineering, Vision College of Jeonju, Jeonbuk 54896, Korea; \\ gslee@jvision.ac.kr \\ 2 Department of Urban Engineering, Jeonbuk National University, Jeonbuk 54896, Korea \\ 3 Department of Mineral Resources and Energy Engineering, Energy Storage and Conversion Engineering of \\ Graduate School, Jeonbuk National University, Jeonbuk 54896, Korea \\ * Correspondence: jwhwang@jbnu.ac.kr (J.-W.H.); chosh@jbnu.ac.kr (S.-H.C.)
}

Citation: Lee, G.; Hwang, J.; Cho, S. A Novel Index to Detect Vegetation in Urban Areas Using UAV-Based Multispectral Images. Appl. Sci. 2021, 11, 3472. https://doi.org/10.3390/ app11083472

Academic Editor: LuÃs Picado Santos

Received: 22 February 2021

Accepted: 8 April 2021

Published: 13 April 2021

Publisher's Note: MDPI stays neutral with regard to jurisdictional claims in published maps and institutional affiliations.

Copyright: (c) 2021 by the authors. Licensee MDPI, Basel, Switzerland. This article is an open access article distributed under the terms and conditions of the Creative Commons Attribution (CC BY) license (https:// creativecommons.org/licenses/by/ $4.0 /)$.
Abstract: Unmanned aerial vehicles (UAVs) equipped with high-resolution multispectral cameras have increasingly been used in urban planning, landscape management, and environmental monitoring as an important complement to traditional satellite remote sensing systems. Interest in urban regeneration projects is on the rise in Korea, and the results of UAV-based urban vegetation analysis are in the spotlight as important data to effectively promote urban regeneration projects. Vegetation indices have been used to obtain vegetation information in a wide area using the multispectral bands of satellites. UAV images have recently been used to obtain vegetation information in a more rapid and precise manner. In this study, multispectral images were acquired using a UAV equipped with a Micasense RedEde MX camera to analyze vegetation indices, such as the Normalized Difference Vegetation Index (NDVI), Green Normalized Difference Vegetation Index (GNDVI), Blue Normalized Difference Vegetation Index (BNDVI), Red Green Blue Vegetation Index (RGBVI), Green Red Vegetation Index (GRVI), and Soil Adjusted Vegetation Index (SAVI). However, in the process of analyzing urban vegetation using the existing vegetation indices, it became clear that the vegetation index values of long-run steel roofing, waterproof coated roofs, and urethane-coated areas are often similar to, or slightly higher than, those of grass. In order to improve the problem of misclassification of vegetation, various equations were tested by combining multispectral bands. Kappa coefficient analysis showed that the squared Red-Blue NDVI index produced the best results when analyzing vegetation reflecting urban land cover. The novel vegetation index developed in this study will be very useful for effective analysis of vegetation in urban areas with various types of land cover, such as long-run steel roofing, waterproof coated roofs, and urethane-coated areas.

Keywords: vegetation index; UAV; multispectral bands; land cover

\section{Introduction}

Globally, extreme heat events have been increasing in frequency and severity, resulting in negative impacts on human health [1-3]. At the regional scale, the "Urban Heat Islands" (UHIs) effect results in urban areas being hotter than nearby rural areas due to impervious surface cover, decreased cooling due to deforestation, anthropogenic heat release, and high concentrations of air pollutants, which can greatly impair air quality [4,5]. With the recent acceleration of urbanization, impervious surfaces, such as buildings, roads, and pavements, have come to completely dominate the urban space, causing an increase in surface temperature compared to that in surrounding rural areas due to their capacity to absorb and retain heat $[6,7]$.

Vegetation considerably regulates local air temperatures [8,9]. However, nearly 88\% of global primary vegetation-covered land in urban areas has been destroyed and replaced by artificial surfaces over the past few decades $[10,11]$. Therefore, in order to create a pleasant residential environment, it is necessary to develop policies to accurately identify 
the distribution of vegetation in urban areas and to effectively manage and maintain this vegetation.

Various vegetation indices are used to classify vegetation area from satellite or Unmanned Aerial Vehicle (UAV) images.

The Normalized Difference Vegetation Index (NDVI), reported by Rouse et al. [12], is one of the most commonly used vegetation indices [13-17]. Many other vegetation indices are also used in research, including the Green Normalized Difference Vegetation Index (GNDVI), Blue Normalized Difference Vegetation Index (BNDVI), Red Green Blue Vegetation Index (RGBVI), Green Red Vegetation Index (GRVI), and Soil Adjusted Vegetation Index (SAVI).

GNDVI effectively represents the properties of chlorophyll in green plants [18,19], and BNDVI may help to analyze the spatial heterogeneity and distribution of chlorophyll $[20,21]$.

Soil background is a major surface component that has a significant impact on the spectral behavior of vegetation canopies in arid grasslands with sparse vegetation cover. To reduce the soil background effect, Huete used a soil adjustment factor to account for first-order soil background variations, and proposed the SAVI [22].

Recently, unmanned aerial vehicles (UAVs) equipped with high-resolution cameras have increasingly been used in environment monitoring as an important complement to traditional satellite remote sensing systems [23].

Since RGBVI and GRVI can monitor vegetation using optical sensors [23-25], these two indices are often employed for vegetation and biomass analysis. Such research uses UAVs equipped with inexpensive optical cameras.

Vegetation indices, which assess the spectroscopic properties of plant chlorophyll using the optical and near-infrared bands, have been used in the field of remote sensing to evaluate vegetation distribution and growth characteristics [26,27]. Vegetation indices have been evaluated using Landsat, SPOT, and MODIS satellite images [16,17,28-37].

Satellite imagery is effective in analyzing vegetation in a large area. However, since the satellite moves only in a fixed orbit, it is difficult to obtain the image at the desired time. In addition, the resolution of multispectral satellite images such as Landsat ETM + has limitations in studies that require very precise analysis. Therefore, in the case of small urban areas, UAV research that can quickly take an image at a desired time is being used a lot. In particular, since the UAV system can be equipped with a multispectral sensor, it is easy to conduct various vegetation studies.

Previous studies on UAV-based vegetation monitoring include the following. Sotille et al. used UAVs to map maritime Antarctic vegetation based on NDVI [38] while Estrany et al. developed a method of detecting sediment linked to vegetation using high-resolution UAV imagery for ecosystem management [39]. Zhao et al. developed an object-oriented vegetation classification method based on fusion of UAV and satellite images [40]. In particular, there have been various studies analyzing vegetation and landscape in urban areas using UAV technology [41-46]

Korea has recently become very interested in urban regeneration projects. Public operators have a strong interest in the realization of urban regeneration programs with the aim of encouraging the physical, social, and economic development of cities in both in the medium and long term $[47,48]$. In order to promote urban regeneration projects, data are needed to effectively support decision-making. Vegetation provides a comfortable living environment and a respite from the heat waves and urban heat island phenomenon that are exacerbated by climate change $[49,50]$.

This study sprang from a fortuitous accident. In the process of making vegetation drawings using vegetation indices such as NDVI, long-run steel roofing, waterproof coated roofs, and urethane-coated areas were misclassified as vegetation. Therefore, this study aimed to develop a novel vegetation index that accurately reflects the characteristics of urban land cover, such as long-run steel roofing, waterproof coated roofs, and urethanecoated areas, using UAV-based multispectral images. 


\section{Materials}

\subsection{Research Process}

The steps were conducted to effectively classify vegetation in urban areas including long-run steel roofing, waterproof coated roofs, and urethane-coated areas as Figure 1.

\begin{tabular}{|c|}
\hline - select study area \\
\hline$\downarrow$ \\
\hline - select ground control points (GCP) \\
\hline - perform a VRS survey \\
\hline$\downarrow$ \\
\hline - set up UAV flight planning \\
\hline $\begin{array}{l}\text { - acquire multispectral images using UAV } \\
\text { with Micasense RedEdge MX sensor }\end{array}$ \\
\hline$\downarrow$ \\
\hline $\begin{array}{l}\text { - merge multispectral images } \\
\text { based on Pix4D Mapper S/W }\end{array}$ \\
\hline $\begin{array}{l}\text { - calculate various vegetation indices } \\
\text { (NDVI, GNDVI, BNDVI, RGBVI, } \\
\text { GRVI, SAVI) by ArcGIS S/W }\end{array}$ \\
\hline$\downarrow$ \\
\hline $\begin{array}{l}\text { - compare the classified vegetation area with the } \\
\text { ground truth, and review the problem of } \\
\text { misclassification of vegetation by land cover }\end{array}$ \\
\hline$\downarrow$ \\
\hline $\begin{array}{l}\text { - derive a novel vegetation index to reflect urban } \\
\text { land cover }\end{array}$ \\
\hline
\end{tabular}

Figure 1. The research process.

First, the study site was selected, and eight ground control points (GCPs) were determined through a Virtual Reference Station (VRS) survey as reference points for the UAV images. After installing a Micasense RedEdge MX sensor on the UAV, a UAV flight plan was established using DJI GS Pro S/W, and multispectral images were acquired through UAV photography.

Next, by merging images using Pix4D Mapper S/W, orthomosaic images were constructed for the blue, green, red, and near-infrared bands. By combining the images for each band using ArcGIS S/W, various vegetation indices, such as the NDVI, GNDVI, BNDVI, RGBVI, GRVI, and SAVI, were calculated.

In addition, by comparing and analyzing the vegetation index values for various land covers in the target area, points showing abnormal values were identified, and sections to be considered when analyzing vegetation in urban areas were reviewed. Finally, a novel vegetation index was derived to effectively analyze the vegetation distribution area reflecting the urban land cover.

\subsection{Study Area}

Figure 2 shows the part of the Vision College of Jeonju-si, located in Jeollabuk-do, Republic of Korea, that was selected as the target site of this study. The area contains vegetation areas, such as trees and lawns, as well as non-vegetation areas, such as an artificial grass playground, playground tracks, urethane basketball courts, long-run steel roofing, and waterproof coated roofs. 


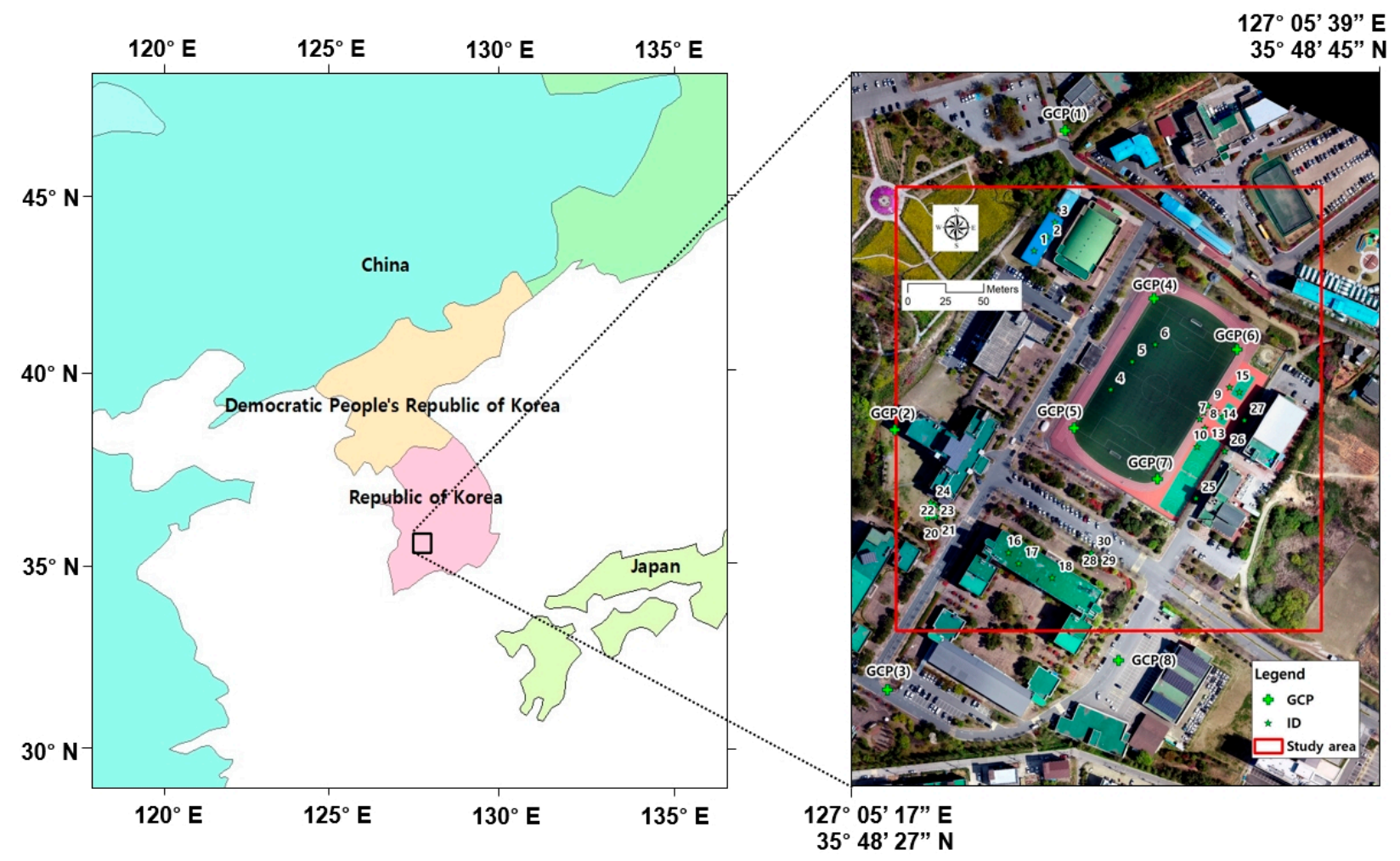

Figure 2. The study area.

\subsection{UAV Image Processing}

Figure 3a shows the DJI Matrice 210 UAV equipped with the Micasense RedEdge MX sensor, which was used to obtain multispectral images. The Micasense RedEdge MX sensor is widely used to analyze vegetation, agricultural management practices, and water quality because it can acquire blue, green, red, and near-infrared spectral images [51-54]. Its resolution is about $8 \mathrm{~cm}$ at an altitude of $120 \mathrm{~m}$, providing very precise image information, and its weight is $231.9 \mathrm{~g}$, which is very light [55], so it has the advantage of allowing sufficient flight time for the DJI Matrice 210, as shown in Table 1.

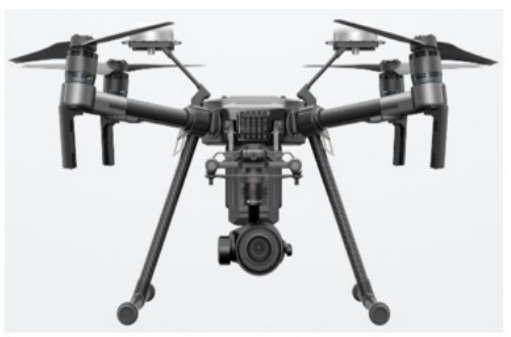

(a) DJI Matrice 210

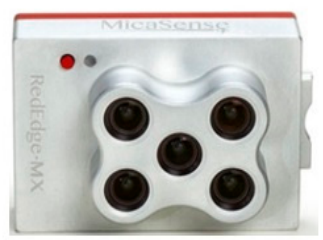

\section{(b) Micasense RedEdge MX}

Figure 3. The Unmanned Aerial Vehicle (UAV) system: (a) DJI Matrice 210, (b) Micasense RedEdge MX. 
Table 1. Specifications of the Micasense RedEdge MX.

\begin{tabular}{cc}
\hline Items & Contents \\
\hline Weight & $231.9 \mathrm{~g}$ \\
Dimensions & $8.7 \mathrm{~cm} \times 5.9 \mathrm{~cm} \times 3.4 \mathrm{~cm}$ \\
Spectral bands & Blue, Green, Red, Red Edge, Near Infrared \\
Ground sample distance & $8 \mathrm{~cm}$ per pixel at $120 \mathrm{~m} \mathrm{AGL}$ \\
Field of view & $47.2^{\circ}$ HFOV \\
Capture rate & 12 -bit RAW \\
\hline
\end{tabular}

The DJI GS Pro S/W was used to establish the UAV flight plan, as shown in Figure 4. The degree of longitudinal and lateral redundancy were designed to be $80 \%$ and $70 \%$, respectively, and photography was performed at a flight altitude of about $100 \mathrm{~m}$ to acquire images with a resolution of $6 \mathrm{~cm}$. Radiometric calibration was performed before the flight using a calibrated reflectance panel (CRP) and the incident light sensor of the Micasense RedEdge MX camera.

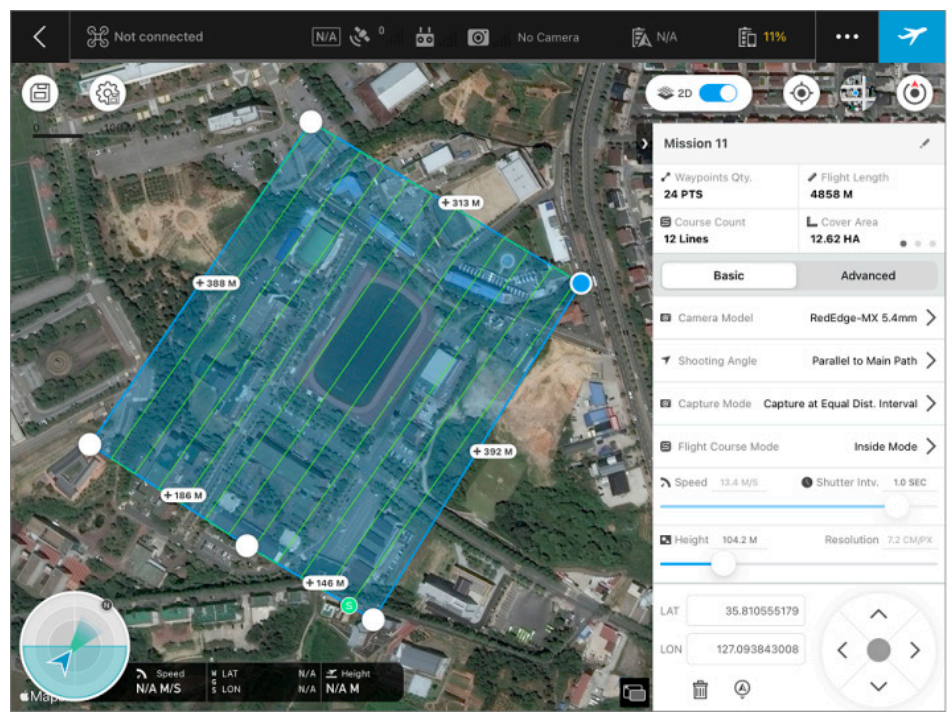

Figure 4. UAV flight planning using the DJI GS Pro S/W.

To secure the positional accuracy of the UAV images, eight GCPs were selected, as shown in Table 2, and the transverse Mercator (TM) coordinates of the GRS80 ellipsoid were acquired through the VRS survey. Each captured image has Universal Transverse Mercator (UTM) coordinates on the WGS84 ellipsoid, obtained through a Global Positioning System (GPS) receiver attached to the UAV. To convert these coordinates into the TM coordinates of the GRS80 ellipsoid used in Korea, the survey results were matched to the GCPs.

Table 2. Coordinates of the ground control points (GCPs).

\begin{tabular}{cccc}
\hline No. & $\mathbf{X}(\mathbf{E})$ & $\mathbf{Y}(\mathbf{N})$ & $\mathbf{Z}$ (EL.m) \\
\hline 1 & $208,205.89$ & $357,135.16$ & 54.925 \\
2 & $208,094.13$ & $356,938.89$ & 51.212 \\
3 & $208,089.28$ & $356,768.06$ & 53.999 \\
4 & $208,264.45$ & $357,025.07$ & 48.135 \\
5 & $208,211.96$ & $356,939.97$ & 48.101 \\
6 & $208,319.01$ & $356,991.52$ & 48.183 \\
7 & $208,266.54$ & $356,906.45$ & 48.116 \\
8 & $208,241.17$ & $356,787.41$ & 49.358 \\
\hline
\end{tabular}


In addition, images from each band were merged using Pix4D Mapper S/W, and index maps were constructed for each red, green, blue, and near-infrared image to calculate the vegetation index (Figure 5).

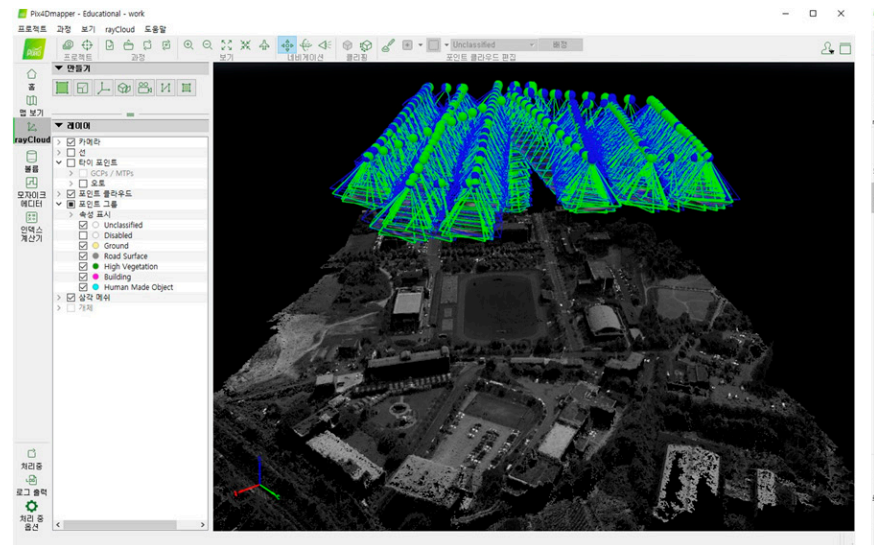

(a) Merging of UAV images

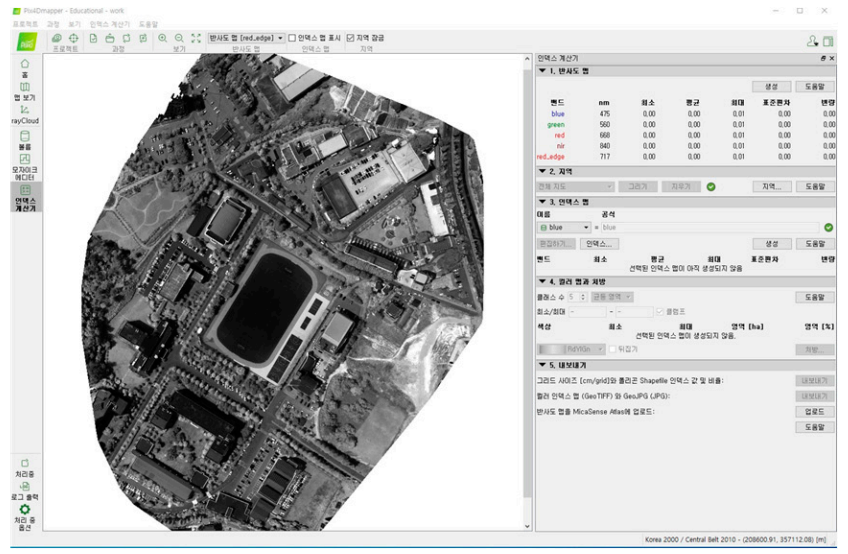

(b) Index map of multispectral image

Figure 5. UAV image processing using Pix4D Mapper S/W.

The following are the general steps of Pix4D Mapper S/W image processing: (1) Image alignment and sparse point cloud building, (2) Identification of GCPs and sparse point cloud optimization, (3) Dense point cloud building, and (4) Construction of an orthomosaic and Digital Surface Model (DSM).

(a) Merging of UAV images

(b) Index map of multispectral image

\section{Vegetation Analysis Using Existing Vegetation Indices}

In this study, various existing vegetation indices were analyzed using ArcGIS S/W from the multispectral images constructed through UAV image processing (Table 3). Figure 6 shows the vegetation index maps of NDVI, GNDVI, BNDVI, RGBVI, GRVI, and SAVI. Table 4 gives the statistical characteristics of each vegetation index.

Table 3. Existing vegetation index equations.

\begin{tabular}{c}
\hline Vegetation Index Equation \\
\hline$N D V I=\frac{\text { NirRed }}{\text { Nir+Red }}$ \\
$G N D V I=\frac{\text { NirGreen }}{\text { Nir+Green }}$ \\
$B N D V I=\frac{\text { NirBlue }}{\text { Nir+Blue }}$ \\
$R G B I=\frac{\text { Green }^{2} \text { Red } * \text { Blue }}{\text { Green }+ \text { Red } * \text { Blue }}$ \\
$G R V I=\frac{\text { GreenRed }_{\text {Green }+ \text { Red }}}{\text { SA }}$ \\
$S A V I=1.5\left(\frac{\text { NirRed }}{\text { Nir }+ \text { Red }+0.5}\right)$ \\
\hline
\end{tabular}




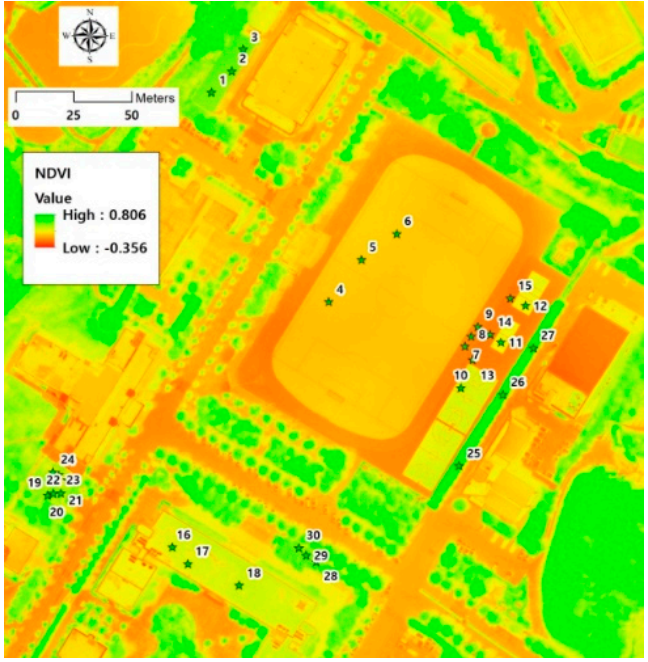

(a) NDVI

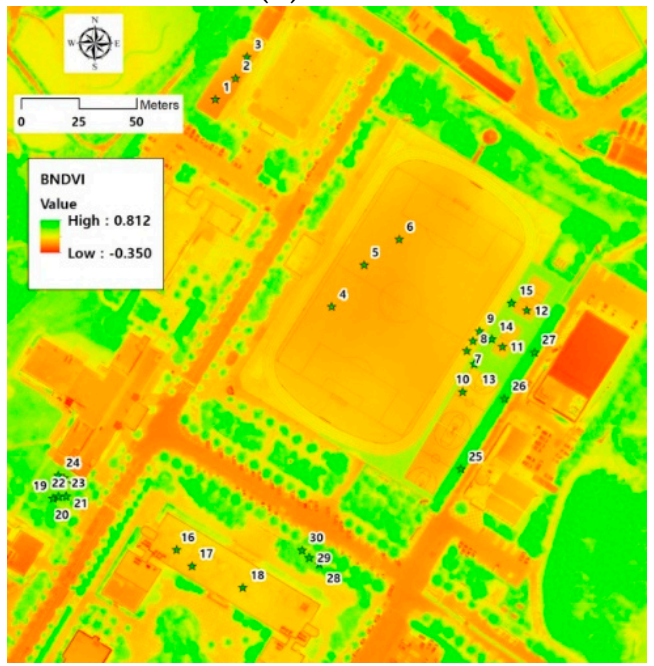

(c) GNDVI

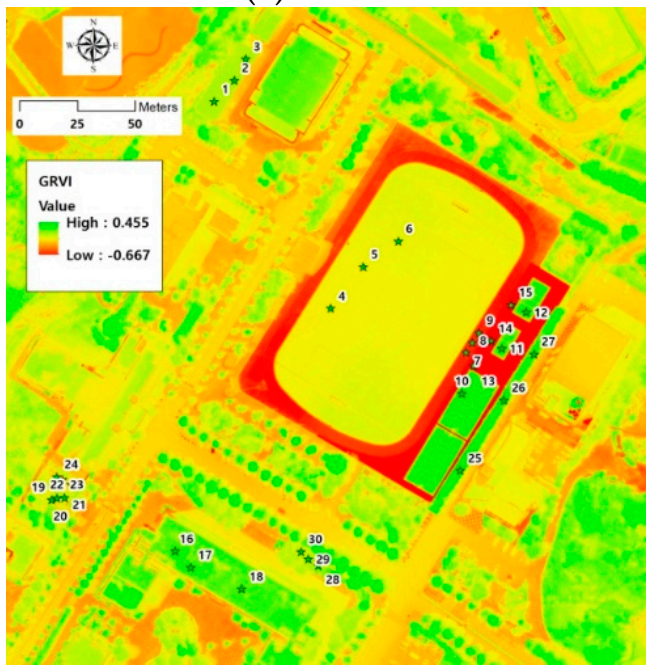

(e) GRVI

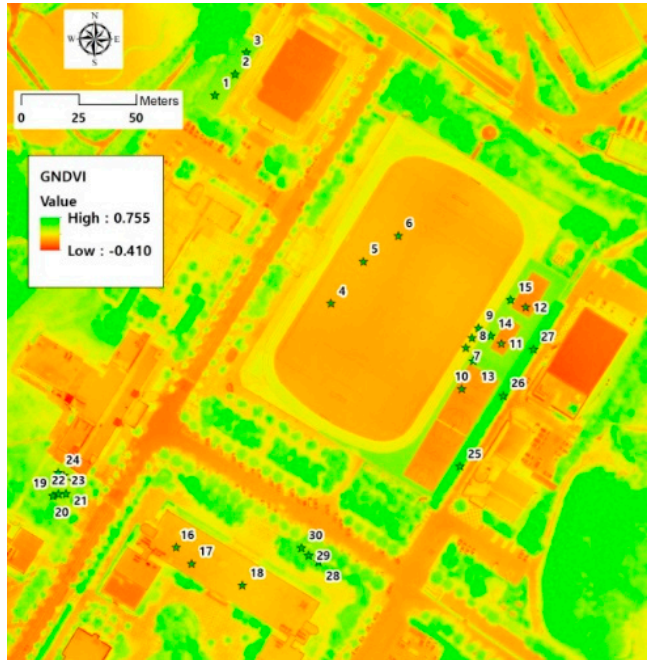

(b) GNDVI

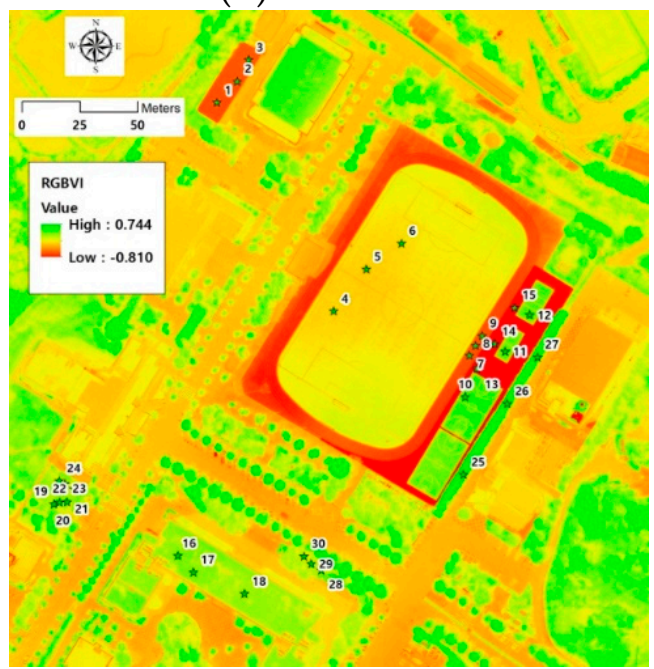

(d) RGBVI

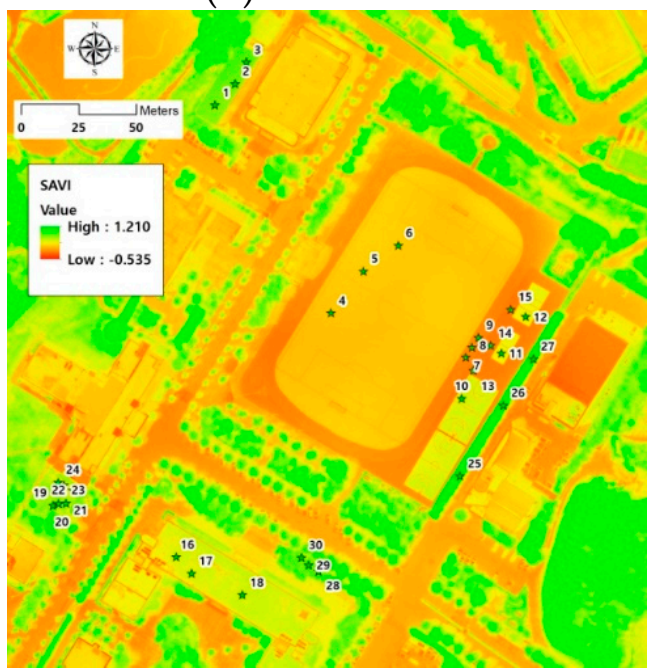

(f) SAVI

Figure 6. Maps produced using existing vegetation index equations. 
The target area contains various types of land cover, such as trees, grass, an artificial grass playground, long-run steel roofing, waterproof coated roofs, and urethane-coated areas. Therefore, as illustrated in Figure 7, a representative location was selected for each type of land cover, and three sample points were chosen for each location.

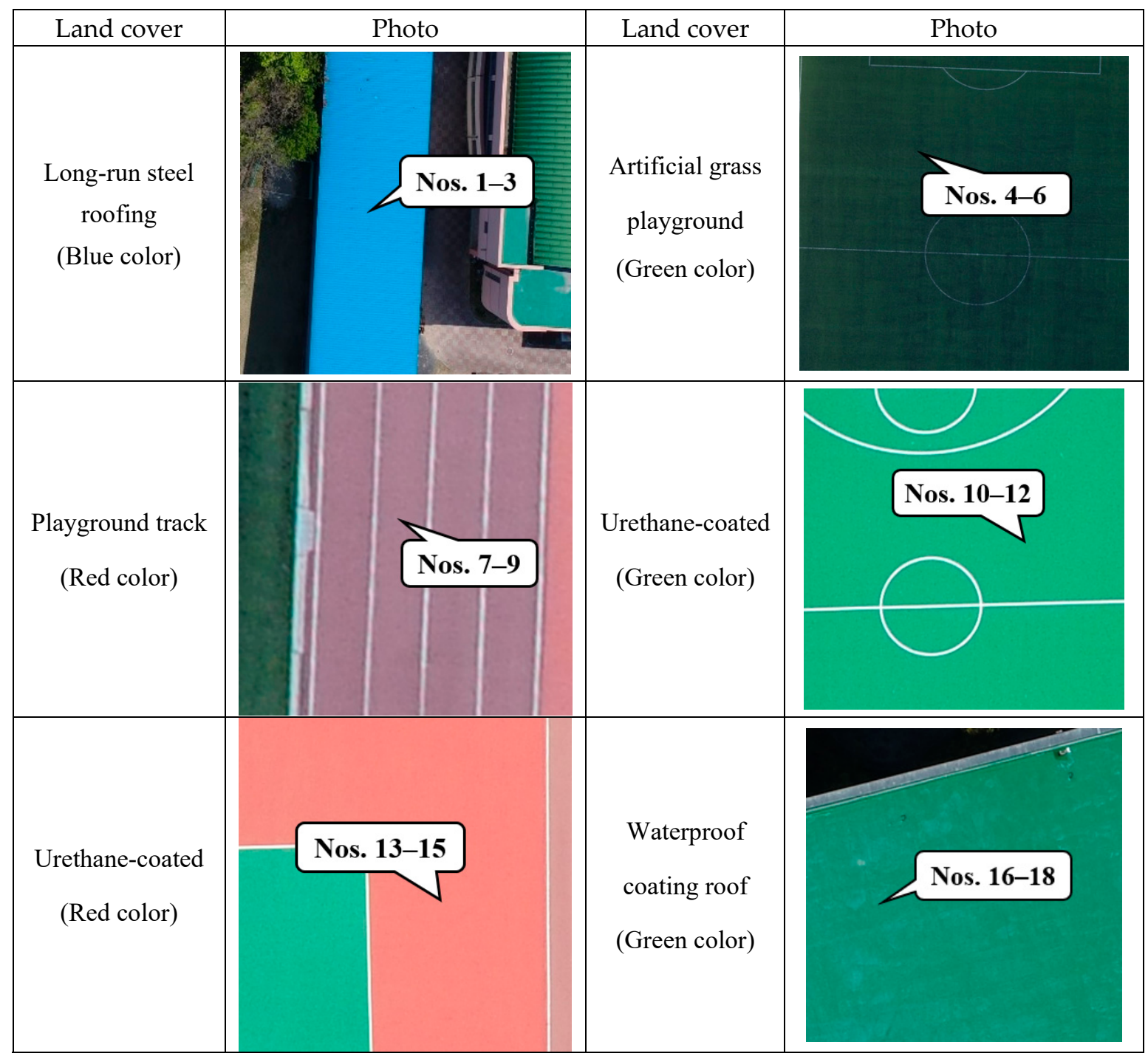

Figure 7. Cont. 


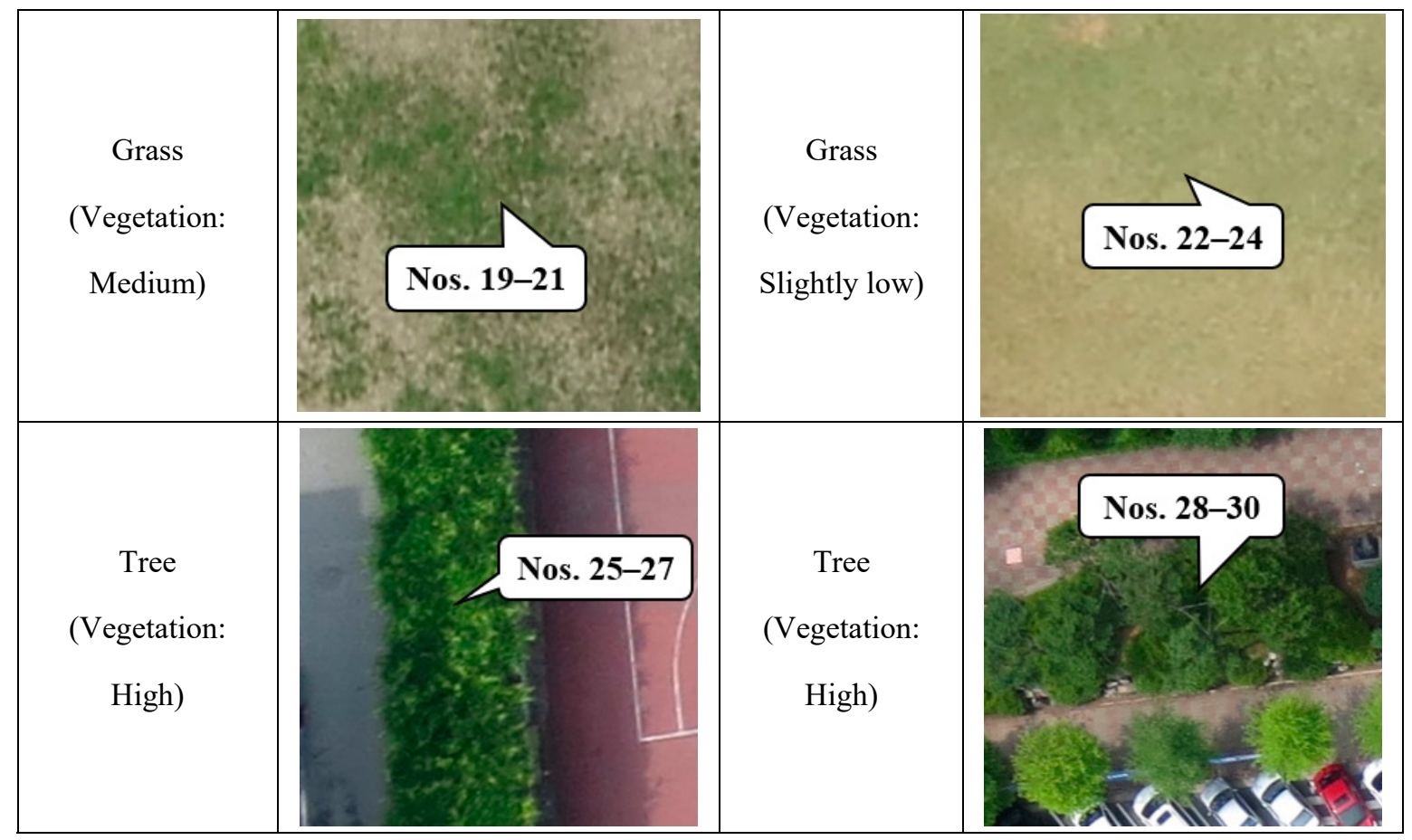

Figure 7. Examples of various types of land cover.

The UAV flight took place on 2 April 2020, in the early spring. At this time of year, the vegetation vitality of trees is high, but the vegetation vitality of grass is medium to low. Grass-covered positions showing medium vegetation vitality (Nos. 19-21) and slightly lower vitality (Nos. 22-24) were selected and compared.

Table 5 shows the results of the six existing vegetation indices for each type of land cover.

When vegetation was classified using NDVI, GNDVI, BNDVI, RGBVI, GRVI, and SAVI, there were locations in which the index values of long-run steel roofing, waterproof coated roofs, and urethane-coated areas were slightly higher than that of grass. Therefore, it was necessary to develop a novel vegetation index suitable for urban areas to effectively address this issue.

Table 4. Characteristics of existing vegetation index maps.

\begin{tabular}{ccccc}
\hline $\begin{array}{c}\text { Vegetation } \\
\text { Index }\end{array}$ & Min & Max & Mean & StD. \\
\hline NDVI & -0.356 & 0.806 & 0.253 & 0.226 \\
GNDVI & -0.410 & 0.755 & 0.232 & 0.173 \\
BNDVI & -0.350 & 0.812 & 0.301 & 0.216 \\
RGBVI & -0.810 & 0.744 & 0.117 & 0.184 \\
GRVI & -0.667 & 0.455 & 0.034 & 0.126 \\
SAVI & -0.535 & 1.210 & 0.380 & 0.339 \\
\hline
\end{tabular}


Table 5. Comparison of vegetation index values by type of land cover using the existing indices.

\begin{tabular}{|c|c|c|c|c|c|c|c|c|c|c|c|c|c|}
\hline \multirow{2}{*}{ No } & \multirow{2}{*}{ Land Cover } & \multicolumn{2}{|c|}{ NDVI } & \multicolumn{2}{|c|}{ GNDVI } & \multicolumn{2}{|c|}{ BNDVI } & \multicolumn{2}{|c|}{ RGBVI } & \multicolumn{2}{|c|}{ GRVI } & \multicolumn{2}{|c|}{ SAVI } \\
\hline & & Value & Mean & Value & Mean & Value & Mean & Value & Mean & Value & Mean & Value & Mean \\
\hline 1 & \multirow{3}{*}{$\begin{array}{l}\text { Long-run steel roofing } \\
\text { (Blue color) }\end{array}$} & 0.48 & \multirow{3}{*}{0.50} & 0.38 & \multirow{3}{*}{0.41} & 0.04 & \multirow{3}{*}{0.08} & -0.24 & \multirow{3}{*}{-0.24} & 0.12 & \multirow{3}{*}{0.11} & 0.72 & \multirow{3}{*}{0.75} \\
\hline 2 & & 0.50 & & 0.41 & & 0.07 & & -0.25 & & 0.11 & & 0.75 & \\
\hline 3 & & 0.53 & & 0.44 & & 0.12 & & -0.23 & & 0.11 & & 0.79 & \\
\hline 4 & \multirow{3}{*}{$\begin{array}{l}\text { Artificial grass playground } \\
\text { (Green color) }\end{array}$} & 0.12 & \multirow{3}{*}{0.14} & 0.09 & \multirow{3}{*}{0.10} & 0.11 & \multirow{3}{*}{0.11} & 0.05 & \multirow{3}{*}{0.04} & 0.03 & \multirow{3}{*}{0.04} & 0.19 & \multirow{3}{*}{0.21} \\
\hline 5 & & 0.15 & & 0.12 & & 0.11 & & 0.01 & & 0.02 & & 0.22 & \\
\hline 6 & & 0.15 & & 0.09 & & 0.11 & & 0.07 & & 0.06 & & 0.22 & \\
\hline 7 & \multirow{3}{*}{$\begin{array}{l}\text { Playground track } \\
\text { (Red color) }\end{array}$} & -0.04 & \multirow{3}{*}{-0.04} & 0.22 & \multirow{3}{*}{0.22} & 0.23 & \multirow{3}{*}{0.24} & -0.24 & & -0.26 & & -0.06 & \\
\hline 8 & & -0.04 & & 0.22 & & 0.23 & & -0.24 & -0.24 & -0.26 & -0.26 & -0.06 & -0.06 \\
\hline 9 & & -0.04 & & 0.23 & & 0.25 & & -0.24 & & -0.26 & & -0.06 & \\
\hline 10 & & 0.32 & & 0.05 & & 0.19 & & 0.40 & & 0.27 & & 0.48 & \\
\hline 11 & Urethane-coated & 0.26 & 0.28 & 0.04 & 0.04 & 0.18 & 0.17 & 0.35 & 0.37 & 0.22 & 0.24 & 0.39 & 0.41 \\
\hline 12 & & 0.24 & & 0.02 & & 0.14 & & 0.34 & & 0.23 & & 0.37 & \\
\hline 13 & & -0.07 & & 0.41 & & 0.46 & & -0.42 & & -0.47 & & -0.11 & \\
\hline 14 & Urethane-coated & -0.07 & -0.07 & 0.39 & 0.40 & 0.46 & 0.46 & -0.37 & -0.39 & -0.44 & -0.45 & -0.10 & -0.11 \\
\hline 15 & & -0.08 & & 0.39 & & 0.46 & & -0.38 & & -0.45 & & -0.12 & \\
\hline 16 & & 0.30 & & 0.09 & & 0.18 & & 0.30 & & 0.21 & & 0.44 & \\
\hline 17 & Waterproot-coated root & 0.30 & 0.32 & 0.09 & 0.11 & 0.18 & 0.20 & 0.31 & 0.30 & 0.22 & 0.22 & 0.45 & 0.48 \\
\hline 19 & & 0.50 & & 0.43 & & 0.59 & & 0.29 & & 0.09 & & 0.74 & \\
\hline 20 & $\begin{array}{l}\text { Grass } \\
\text { (Veotation. Middle) }\end{array}$ & 0.50 & 0.52 & 0.41 & 0.43 & 0.58 & 0.60 & 0.33 & 0.33 & 0.11 & 0.11 & 0.75 & 0.78 \\
\hline 21 & & 0.56 & & 0.46 & & 0.63 & & 0.37 & & 0.14 & & 0.84 & \\
\hline 22 & & 0.35 & & 0.33 & & 0.50 & & 0.24 & & 0.03 & & 0.53 & \\
\hline 23 & Grass & 0.27 & 0.29 & 0.29 & 0.30 & 0.43 & 0.45 & 0.14 & 0.17 & -0.02 & -0.01 & 0.40 & 0.43 \\
\hline 24 & & 0.24 & & 0.27 & & 0.42 & & 0.13 & & -0.03 & & 0.36 & \\
\hline 25 & & 0.68 & & 0.51 & & 0.68 & & 0.49 & & 0.26 & & 1.02 & \\
\hline 26 & Iree & 0.71 & 0.70 & 0.56 & 0.54 & 0.73 & 0.72 & 0.51 & 0.50 & 0.26 & 0.25 & 1.07 & 1.05 \\
\hline 27 & (Vegetation: High) & 0.71 & & 0.57 & & 0.73 & & 0.49 & & 0.24 & & 1.07 & \\
\hline 28 & & 0.63 & & 0.47 & & 0.61 & & 0.41 & & 0.23 & & 0.95 & \\
\hline 29 & Iree & 0.67 & 0.66 & 0.40 & 0.44 & 0.65 & 0.65 & 0.63 & 0.54 & 0.36 & 0.31 & 1.00 & 0.99 \\
\hline 30 & & 0.69 & & 0.47 & & 0.68 & & 0.57 & & 0.33 & & 1.03 & \\
\hline
\end{tabular}




\section{A Novel Vegetation Index That Accurately Reflects Urban Land Cover}

Thus, in urban areas, use of existing vegetation indices (NDVI, GNDVI, BNDVI, RGBVI, GRVI, and SAVI) results in misclassification of long-run steel roofing, urethanecoated, and waterproof coated areas as vegetation.

To address this problem, many equations were created by combining the blue, green, red, and nir bands, and three equations that can be used for urban vegetation analysis were finally selected through a manual process as Table 6 . Finally, the optimal vegetation index was suggested by verifying the result of vegetation classification for each type of land cover.

Table 6. A novel vegetation index equation.

\begin{tabular}{|c|c|}
\hline \multicolumn{2}{|c|}{ Vegetation Index Equation } \\
\hline $\begin{array}{l}\text { squared Blue-Green NDVI index } \\
\text { squared Red-Green NDVI index } \\
\text { squared Red-Blue NDVI index }\end{array}$ & $\begin{array}{l}\frac{\mathrm{Nir}^{2} \text { Blue } * \text { Green }}{\mathrm{Nir}^{2}+\text { Blue } * \text { Green }} \\
\mathrm{Nir}^{2} \text { Red } * \text { Green } \\
\text { Nir }^{2}+\text { Red } * \text { Green } \\
\text { Nir } \\
\text { Nir }^{2}+\text { Red } * \text { Blue } \\
\text { Blue }\end{array}$ \\
\hline
\end{tabular}

Table 6 shows the results of applying the novel vegetation index equation. Figures 8-10 show the vegetation index map for each equation and the results of vegetation classification according to the threshold value. The threshold value for vegetation classification was applied in consideration of the vegetation index of lower-vitality grass (Nos. 22-24).

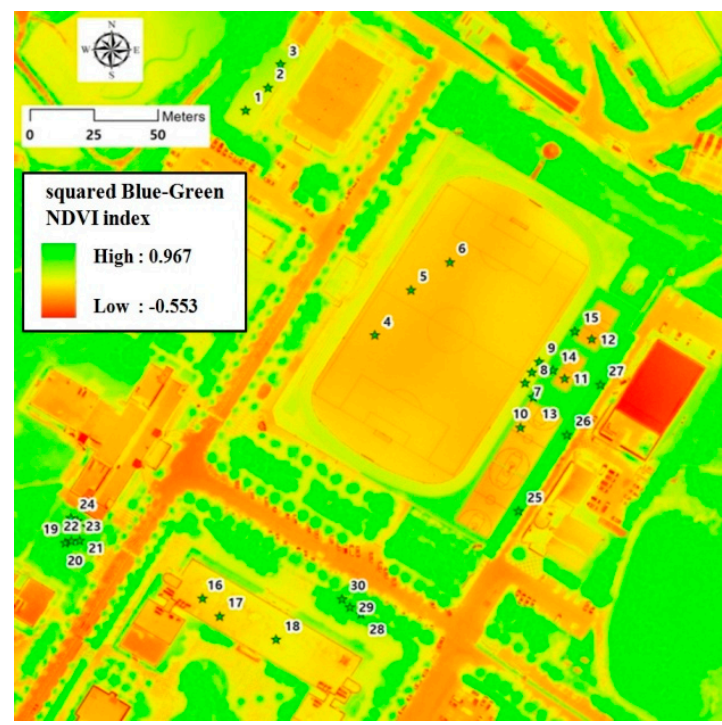

(a) Vegetation index map

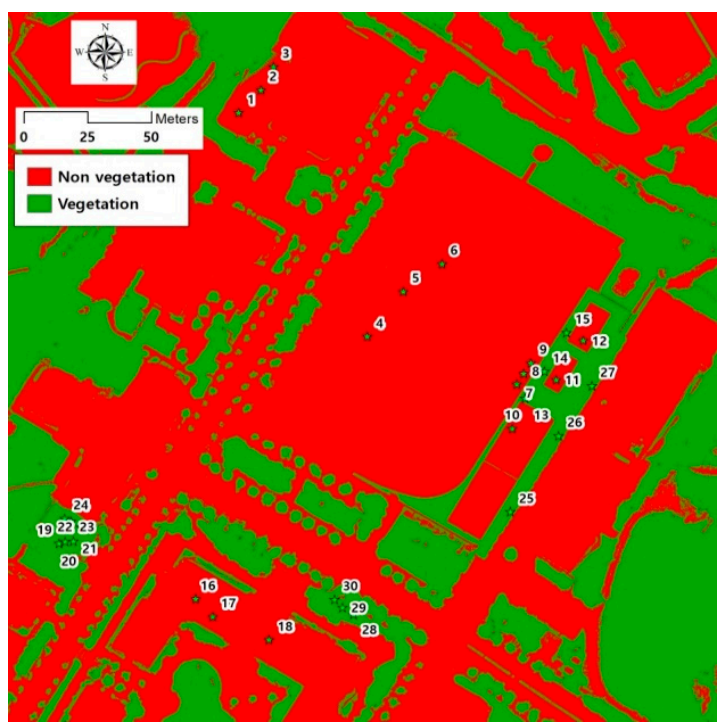

(b) Vegetation map (threshold value $>0.62$ )

Figure 8. Vegetation index map and vegetation map based on the squared Blue-Green Normalized Difference Vegetation Index (NDVI) index. 


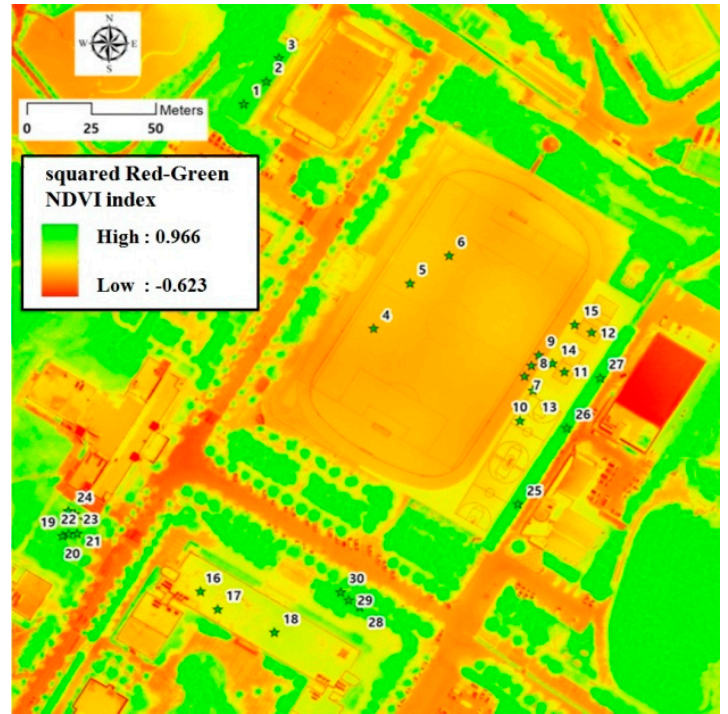

(a) Vegetation index map

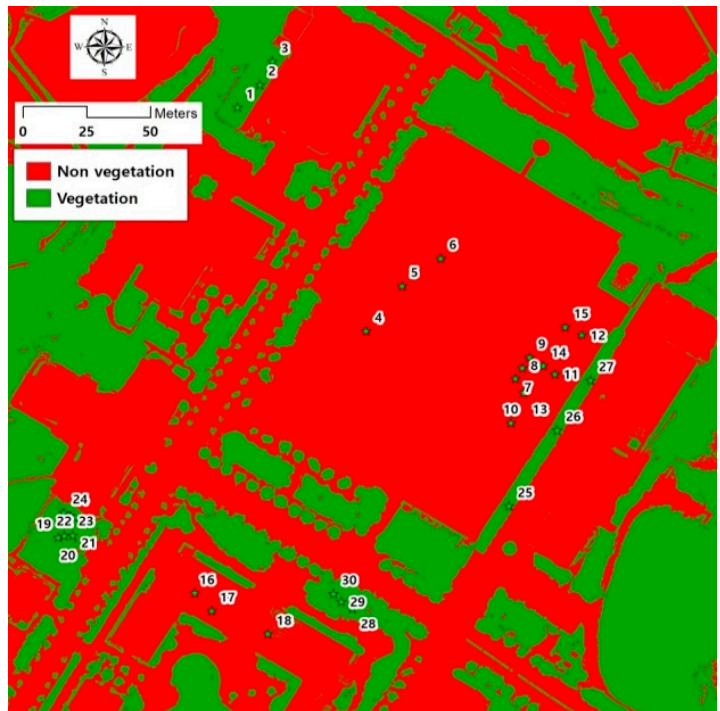

(b) Vegetation map (threshold value $>0.48$ )

Figure 9. Vegetation index map and vegetation map based on the squared Red-Green NDVI index.

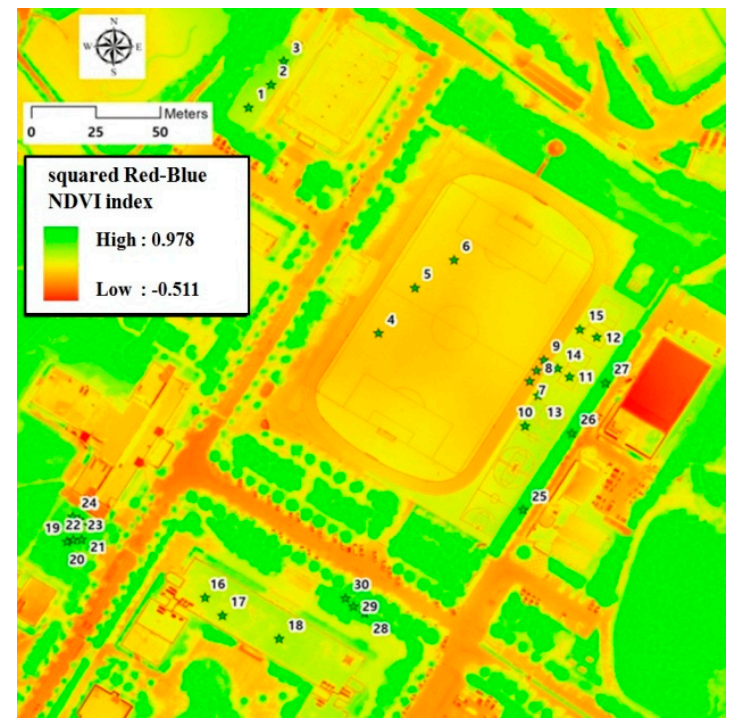

(a) Vegetation index map

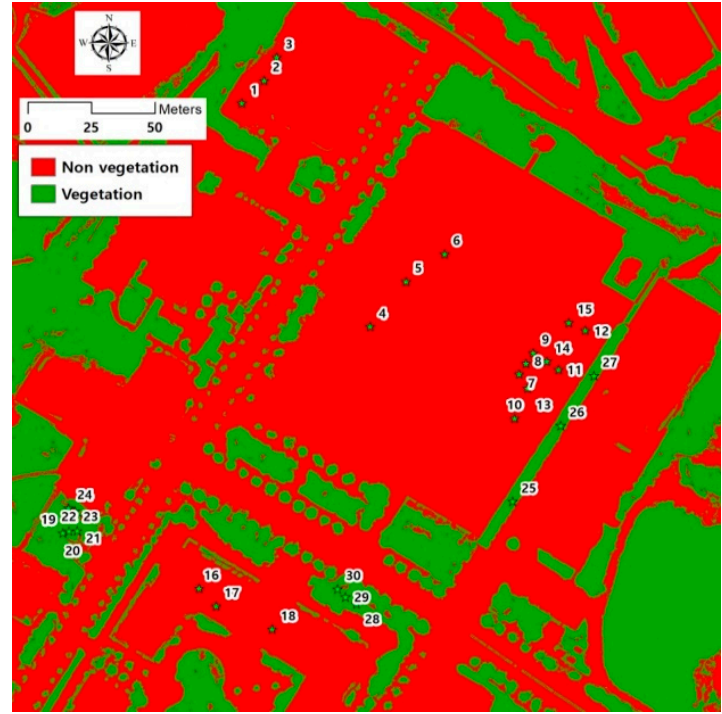

(b) Vegetation map (threshold value $>0.61$ )

Figure 10. Vegetation index map and vegetation map based on the squared Red-Blue NDVI index.

First, using the squared Blue-Green NDVI index, the vegetation indices of the red urethane-coated areas (Nos. 13-15) ranged from 0.72 to 0.74 , which were slightly higher than the values of lower-vitality grass (Nos. 22-24). Therefore, as shown in Figure 8b, when 0.62 (the minimum value of lower-vitality grass) was set as the threshold value, the red urethane-coated areas were misclassified as vegetation.

Second, using the squared Red-Green NDVI index, the vegetation indices of the longrun steel roofing (Nos. 1-3) were between 0.73 and 0.78 , which were similar to the values of the medium-vitality grass (Nos. 19-21) and higher than those of the lower-vitality grass (Nos. 22-24). Therefore, as shown in Figure 9b, when 0.48 (the minimum value of the lower-vitality grass) was set as the threshold value, the areas with long-run steel roofing were misclassified as vegetation.

Finally, using the squared Red-Blue NDVI index, the vegetation indices of the long-run steel roofing (Nos. 1-3), urethane-coated (Nos. 10-15), and waterproof-coated (Nos. 16-18) 
areas were all lower than the vegetation index of lower-vitality grass (Nos. 22-24). Therefore, as shown in Figure 10b, when 0.61 (the minimum value of the lower-vitality grass) was set as the threshold value, only areas with trees and grass were classified as vegetation areas, see Table 7 .

Table 7. Comparison of vegetation index values by type of land cover using the novel indices.

\begin{tabular}{|c|c|c|c|c|c|c|c|}
\hline \multirow[t]{2}{*}{ No } & \multirow[t]{2}{*}{ Land Cover } & \multicolumn{2}{|c|}{$\begin{array}{c}\text { Squared Blue-Green } \\
\text { NDVI Index }\end{array}$} & \multicolumn{2}{|c|}{$\begin{array}{l}\text { Squared Red-Green } \\
\text { NDVI Index }\end{array}$} & \multicolumn{2}{|c|}{$\begin{array}{l}\text { Squared Red-Blue } \\
\text { NDVI Index }\end{array}$} \\
\hline & & Value & Mean & Value & Mean & Value & Mean \\
\hline 1 & \multirow{3}{*}{$\begin{array}{l}\text { Long-run steel roofing } \\
\text { (Blue color) }\end{array}$} & 0.42 & \multirow{3}{*}{0.47} & 0.73 & \multirow{3}{*}{0.76} & 0.51 & \multirow{3}{*}{0.52} \\
\hline 2 & & 0.46 & & 0.75 & & 0.53 & \\
\hline 3 & & 0.53 & & 0.78 & & 0.52 & \\
\hline 4 & \multirow{3}{*}{$\begin{array}{c}\text { Artificial grass playground } \\
\text { (Green color) }\end{array}$} & 0.20 & \multirow{3}{*}{0.21} & 0.21 & \multirow{3}{*}{0.24} & 0.23 & \multirow{3}{*}{0.25} \\
\hline 5 & & 0.23 & & 0.27 & & 0.25 & \\
\hline 6 & & 0.20 & & 0.24 & & 0.25 & \\
\hline 7 & \multirow{3}{*}{$\begin{array}{l}\text { Playground track } \\
\text { (Red color) }\end{array}$} & 0.43 & \multirow{3}{*}{0.43} & 0.18 & \multirow{3}{*}{0.18} & 0.19 & \multirow{3}{*}{0.20} \\
\hline 8 & & 0.43 & & 0.17 & & 0.19 & \\
\hline 9 & & 0.45 & & 0.19 & & 0.21 & \\
\hline 10 & \multirow{3}{*}{$\begin{array}{l}\text { Urethane-coated } \\
\text { (Green color) }\end{array}$} & 0.24 & \multirow{3}{*}{0.21} & 0.37 & \multirow{3}{*}{0.31} & 0.48 & \multirow{3}{*}{0.43} \\
\hline 11 & & 0.22 & & 0.30 & & 0.43 & \\
\hline 12 & & 0.15 & & 0.26 & & 0.37 & \\
\hline 13 & \multirow{3}{*}{$\begin{array}{l}\text { Urethane-coated } \\
\text { (Red color) }\end{array}$} & 0.74 & \multirow{3}{*}{0.73} & 0.35 & \multirow{3}{*}{0.33} & 0.41 & \multirow{3}{*}{0.40} \\
\hline 14 & & 0.72 & & 0.33 & & 0.41 & \\
\hline 15 & & 0.72 & & 0.32 & & 0.39 & \\
\hline 16 & \multirow{3}{*}{$\begin{array}{l}\text { Waterproof-coated roof } \\
\text { (Green color) }\end{array}$} & 0.27 & \multirow{3}{*}{0.30} & 0.38 & \multirow{3}{*}{0.41} & 0.46 & \multirow{3}{*}{0.48} \\
\hline 17 & & 0.27 & & 0.38 & & 0.46 & \\
\hline 18 & & 0.36 & & 0.47 & & 0.54 & \\
\hline 19 & & 0.81 & & 0.76 & & 0.84 & \\
\hline 20 & $\begin{array}{c}\text { Grass } \\
\text { (Veoretation. medium) }\end{array}$ & 0.80 & 0.82 & 0.76 & 0.78 & 0.84 & 0.85 \\
\hline 21 & & 0.84 & & 0.81 & & 0.88 & \\
\hline 22 & & 0.71 & & 0.61 & & 0.73 & \\
\hline 23 & $\begin{array}{l}\text { Grass } \\
\text { (Vegetation. Sliohtly low }\end{array}$ & 0.64 & 0.66 & 0.52 & 0.54 & 0.63 & 0.66 \\
\hline 24 & & 0.62 & & 0.48 & & 0.61 & \\
\hline 25 & & 0.89 & & 0.88 & & 0.93 & \\
\hline 26 & $\begin{array}{l}\text { Iree } \\
\text { (Vegetation } \text { High) }\end{array}$ & 0.91 & 0.91 & 0.91 & 0.90 & 0.95 & 0.94 \\
\hline 27 & (Vegetation: High) & 0.92 & & 0.91 & & 0.95 & \\
\hline 28 & & 0.84 & & 0.85 & & 0.90 & \\
\hline 29 & Tree & 0.83 & 0.85 & 0.84 & 0.85 & 0.92 & 0.92 \\
\hline 30 & (Vegetation: High) & 0.87 & & 0.87 & & 0.93 & \\
\hline
\end{tabular}

To quantitatively verify the novel vegetation index proposed in this study, five validation points were selected for each type of land cover through field surveys. Among these points, twenty validation points in grass and trees were classified as vegetation, while thirty validation points in the areas with long-run steel roofing, artificial playgrounds, playground tracks, urethane coatings, and waterproof coated roofs were classified as non-vegetation.

Figures 11-13 show the validation points for each type of land cover on the vegetation map created by applying the novel vegetation index equation. Table 8 shows the kappa coefficient for the comparison between the novel vegetation map and the ground truth results. The kappa coefficients of the squared Blue-Green NDVI index and squared RedGreen NDVI index were both 0.8 , and the kappa coefficient of the squared Red-Blue NDVI index was the highest, at 1.0. Therefore, the squared Red-Blue NDVI index was found to be the most effective for vegetation analysis, reflecting the characteristics of urban land cover. 


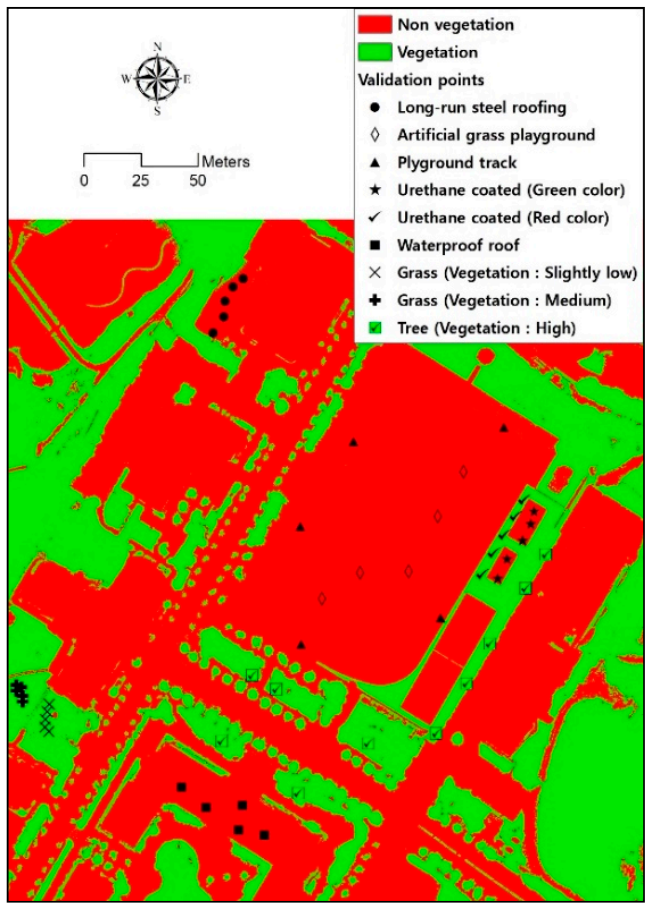

Figure 11. Vegetation map and validation points based on the squared Blue-Green NDVI index.

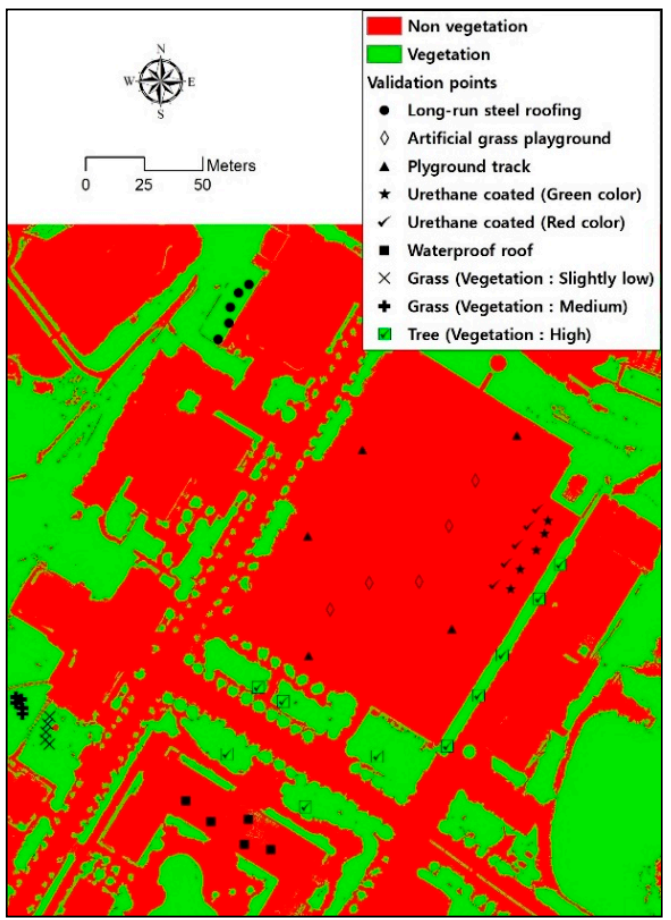

Figure 12. Vegetation map and validation points based on the squared Red-Green NDVI index. 


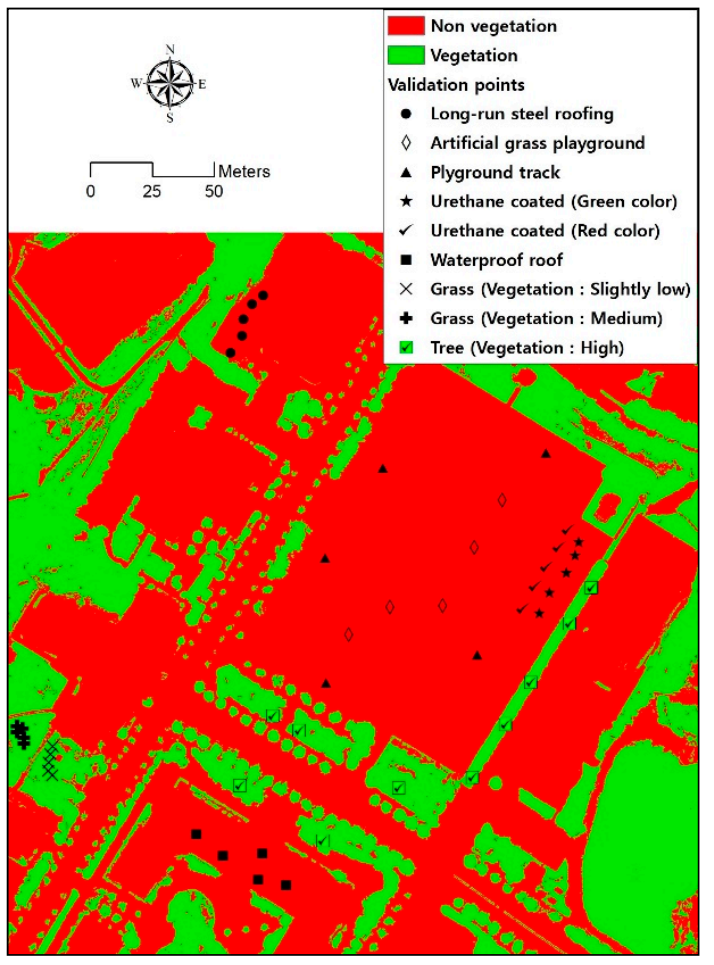

Figure 13. Vegetation map and validation points based on the squared Red-Blue NDVI index.

Table 8. Kappa coefficient analysis for vegetation classification.

\begin{tabular}{ccccccc}
\hline Ground Truth & \multicolumn{2}{c}{ Squared Blue-Green NDVI Index } & \multicolumn{2}{c}{ Squared Red-Green NDVI Index } & \multicolumn{2}{c}{ Squared Red-Blue NDVI Index } \\
\cline { 2 - 7 } & Vegetation & Non-Vegetation & Vegetation & Non-Vegetation & Vegetation & Non-Vegetation \\
\hline $\begin{array}{c}\text { Vegetation } \\
(20 \text { points) }\end{array}$ & 20 & 0 & 20 & 0 & 20 & 0 \\
\hline $\begin{array}{c}\text { Non-vegetation } \\
\text { (30 points) }\end{array}$ & 5 & 25 & 5 & 25 & 0 & 30 \\
\hline $\begin{array}{c}\text { Kappa } \\
\text { coefficient }\end{array}$ & 0.8 & & 0.8 & 1.0 \\
\hline
\end{tabular}

Existing studies using UAV have focused mainly on analyzing vegetation and topography in urban areas [41-46]. There have been studies to detect green-roof using the supervised classification method based on UAV images, but not to develop the vegetation index considering green-roof [41]. Compared with the existing UAV studies, the differences of the results performed in this study were added to the text. Therefore, the new index developed in this study will be a very effective method for classifying vegetation in urban areas with various land covers.

\section{Conclusions}

Accurate vegetation data are vital in various fields, such as urban planning, landscaping, and water quality analysis. In recent years, in order to effectively promote urban regeneration projects, research efforts have attempted to quantitatively analyze the distribution of vegetation in cities using satellite images or UAV images. In particular, vegetation indices, such as NDVI, are widely used for vegetation analysis using remote sensing technologies, such as satellite images and UAV images.

Various types of land cover, such as long-run steel roofing, waterproof coated roofs, and urethane-coated areas, exist in urban areas, and this study found that existing vegetation indices assign inappropriately high values to such areas. Therefore, in this study, 
existing vegetation indices, such as NDVI, GNDVI, BNDVI, RGBVI, GRVI, and SAVI, were used to quantitatively analyze the vegetation index values of different types of land cover. This was done based on high-resolution multispectral images taken by a UAV equipped with a Micasense RedEde MX camera.

As mentioned above, the vegetation index values of long-run steel roofing, waterproof coated roofs, and urethane-coated areas were similar to or higher than those of grass with a slightly low degree of vitality. To address the problem of misclassification according to the characteristics of urban land cover, a test was conducted by combining multiple spectral bands. Finally, three equations were selected and analyzed.

According to a kappa coefficient analysis, the squared Red-Blue NDVI index, which was created by combining information from the blue, red, and near-infrared bands, most accurately reflected the characteristics of urban land cover. The novel vegetation index presented in this study is expected to be very useful in analyzing the vegetation in regions with various types of land cover when conducting urban regeneration projects in the future.

Author Contributions: Conceptualization, G.-S.L. and S.-H.C.; methodology, G.-S.L. G.H. and S.-H.C.; investigation, G.-S.L. and S.-H.C.; writing-original draft preparation, G.-S.L. G.H. and S.-H.C.; writing-review and editing, G.-S.L. G.H. and S.-H.C.; visualization, G.-S.L. and S.-H.C.; supervision. G.H. and S.-H.C.; project administration, G.H. and S.-H.C. All authors have read and agreed to the published version of the manuscript

Funding: This research was supported by a grant (21TSRD-B151228-03) from the Urban Declining Area Regenerative Capacity-Enhancing Technology Research Program funded by the Ministry of Land, Infrastructure and Transport of the Korean government.

Institutional Review Board Statement: Not applicable.

Informed Consent Statement: Not applicable.

Data Availability Statement: Not applicable.

Conflicts of Interest: The authors declare no conflict of interest.

\section{References}

1. Fahad, G.R.; Nazari, R.; Bhavsar, P.; Jalayer, M.; Karimi, M. A decision-support framework for emergency evacuation planning during extreme storm events. Transp. Res. Part D Transp. Environ. 2019, 77, 589-605. [CrossRef]

2. Sabrin, S.; Karimi, M.; Nazari, R. Developing Vulnerability Index to Quantify Urban Heat Islands Effects Coupled with Air Pollution: A Case Study of Camden, NJ. ISPRS Int. J. Geo-Inf. 2020, 9, 349. [CrossRef]

3. Uddin, N.; Islam, A.S.; Bala, S.K.; Islam, G.T.; Adhikary, S.; Saha, D.; Haque, S.; Fahad, G.R.; Akter, R. Mapping of climate vulnerability of the coastal region of Bangladesh using principal component analysis. Appl. Geogr. 2019, 102, 47-57. [CrossRef]

4. Peng, J.; Hu, Y.; Dong, J.; Liu, Q.; Liu, Y. Quantifying spatial morphology and connectivity of urban heat islands in a megacity: A radius approach. Sci. Total. Environ. 2020, 714, 136792. [CrossRef] [PubMed]

5. Sabrin, S.; Karimi, M.; Nazari, R.; Pratt, J.; Bryk, J. Effects of Different Urban-Vegetation Morphology on the Canopy-level Thermal Comfort and the Cooling Benefits of Shade Trees: Case-study in Philadelphia. Sustain. Cities Soc. 2021, 66, 102684. [CrossRef]

6. Voogt, J.; Oke, T. Thermal remote sensing of urban climates. Remote. Sens. Environ. 2003, 86, 370-384. [CrossRef]

7. Ziter, C.D.; Pedersen, E.J.; Kucharik, C.J.; Turner, M.G. Scale-dependent interactions between tree canopy cover and impervious surfaces reduce daytime urban heat during summer. Proc. Natl. Acad. Sci. USA 2019, 116, 7575-7580. [CrossRef] [PubMed]

8. Ellison, D.; Morris, C.E.; Locatelli, B.; Sheil, D.; Cohen, J.; Murdiyarso, D.; Gutierrez, V.; van Noordwijk, M.; Creed, I.F.; Pokorny, J.; et al. Trees, forests and water: Cool insights for a hot world. Glob. Environ. Chang. 2017, 43, 51-61. [CrossRef]

9. Su, Y.; Liu, L.; Wu, J.; Chen, X.; Shang, J.; Ciais, P.; Zhou, G.; Lafortezza, R.; Wang, Y.; Yuan, W.; et al. Quantifying the biophysical effects of forests on local air temperature using a novel three-layered land surface energy balance model. Environ. Int. 2019, 132, 105080. [CrossRef] [PubMed]

10. D'Amour, C.B.; Reitsma, F.; Baiocchi, G.; Barthel, S.; Güneralp, B.; Erb, K.-H.; Haberl, H.; Creutzig, F.; Seto, K.C. Future urban land expansion and implications for global croplands. Proc. Natl. Acad. Sci. USA 2017, 114, 8939-8944. [CrossRef] [PubMed]

11. Seto, K.C.; Guneralp, B.; Hutyra, L.R. Global forecasts of urban expansion to 2030 and direct impacts on biodiversity and carbon pools. Proc. Natl. Acad. Sci. USA 2012, 109, 16083-16088. [CrossRef] [PubMed]

12. Rouse, J.W.; Haas, R.H.; Schell, J.A.; Deering, D.W. Monitoring vegetation systems in the Great Plains with ERTS. NASA Spec. Publ. 1974, 351, 309.

13. Jarchow, C.J.; Nagler, P.L.; Glenn, E.P. Greenup and evapotranspiration following the Minute 319 pulse flow to Mexico: An analysis using Landsat 8 Normalized Difference Vegetation Index (NDVI) data. Ecol. Eng. 2017, 106, 776-783. [CrossRef] 
14. Zhe, M.; Zhang, X. Time-lag effects of NDVI responses to climate change in the Yamzhog Yumco Basin, South Tibet. Ecol. Indic. 2021, 124, 107431. [CrossRef]

15. Gascon, M.; Cirach, M.; Martínez, D.; Dadvand, P.; Valentín, A.; Plasència, A.; Nieuwenhuijsen, M.J. Normalized difference vegetation index (NDVI) as a marker of surrounding greenness in epidemiological studies: The case of Barcelona city. Urban For. Urban Green. 2016, 19, 88-94. [CrossRef]

16. Lanorte, A.; Lasaponara, R.; Lovallo, M.; Telesca, L. Fisher-Shannon information plane analysis of SPOT/VEGETATION Normalized Difference Vegetation Index (NDVI) time series to characterize vegetation recovery after fire disturbance. Int. J. Appl. Earth Obs. Geoinf. 2014, 26, 441-446. [CrossRef]

17. Rhyma, P.; Norizah, K.; Hamdan, O.; Faridah-Hanum, I.; Zulfa, A. Integration of normalised different vegetation index and Soil-Adjusted Vegetation Index for mangrove vegetation delineation. Remote. Sens. Appl. Soc. Environ. 2020, 17, 100280. [CrossRef]

18. Taddeo, S.; Dronova, I.; Depsky, N. Spectral vegetation indices of wetland greenness: Responses to vegetation structure, composition, and spatial distribution. Remote. Sens. Environ. 2019, 234, 111467. [CrossRef]

19. Dixon, D.J.; Callow, J.N.; Duncan, J.M.; Setterfield, S.A.; Pauli, N. Satellite prediction of forest flowering phenology. Remote. Sens. Environ. 2021, 255, 112197. [CrossRef]

20. Hatton, N.M.; Menke, E.; Sharda, A.; van der Merwe, D.; Schapaugh, W. Assessment of sudden death syndrome in soybean through multispectral broadband remote sensing aboard small unmanned aerial systems. Comput. Electron. Agric. 2019, 167, 105094. [CrossRef]

21. Kleefeld, A.; Gypser, S.; Herppich, W.B.; Bader, G.; Veste, M. Identification of spatial pattern of photosynthesis hotspots in mossand lichen-dominated biological soil crusts by combining chlorophyll fluorescence imaging and multispectral BNDVI images. Pedobiologia 2018, 68, 1-11. [CrossRef]

22. Huete, A. A soil-adjusted vegetation index (SAVI). Remote. Sens. Environ. 1988, 25, 295-309. [CrossRef]

23. Guo, Z.-C.; Wang, T.; Liu, S.-L.; Kang, W.-P.; Chen, X.; Feng, K.; Zhang, X.-Q.; Zhi, Y. Biomass and vegetation coverage survey in the Mu Us sandy land-Based on unmanned aerial vehicle RGB images. Int. J. Appl. Earth Obs. Geoinf. 2021, $94,102239$. [CrossRef]

24. Bendig, J.; Yu, K.; Aasen, H.; Bolten, A.; Bennertz, S.; Broscheit, J.; Gnyp, M.L.; Bareth, G. Combining UAV-based plant height from crop surface models, visible, and near infrared vegetation indices for biomass monitoring in barley. Int. J. Appl. Earth Obs. Geoinf. 2015, 39, 79-87. [CrossRef]

25. Khadanga, G.; Jain, K. Tree Census Using Circular Hough Transform and GRVI. Procedia Comput. Sci. 2020, 171, 389-394. [CrossRef]

26. Thomas, J.R.; Gausman, H.W. Leaf Reflectance vs. Leaf Chlorophyll and Carotenoid Concentrations for Eight Crops 1. Agron. J. 1977, 69, 799-802. [CrossRef]

27. Zhang, F.; Zhang, L.-W.; Shi, J.-J.; Huang, J.-F. Soil Moisture Monitoring Based on Land Surface Temperature-Vegetation Index Space Derived from MODIS Data. Pedosphere 2014, 24, 450-460. [CrossRef]

28. Bai, T.; Zhang, N.; Mercatoris, B.; Chen, Y. Jujube yield prediction method combining Landsat 8 Vegetation Index and the phenological length. Comput. Electron. Agric. 2019, 162, 1011-1027. [CrossRef]

29. Rokni, K.; Musa, T.A. Normalized difference vegetation change index: A technique for detecting vegetation changes using Landsat imagery. Catena 2019, 178, 59-63. [CrossRef]

30. Roy, D.; Kovalskyy, V.; Zhang, H.; Vermote, E.; Yan, L.; Kumar, S.; Egorov, A. Characterization of Landsat-7 to Landsat-8 reflective wavelength and normalized difference vegetation index continuity. Remote. Sens. Environ. 2016, 185, 57-70. [CrossRef]

31. Xie, Y.; Wang, P.; Bai, X.; Khan, J.; Zhang, S.; Li, L.; Wang, L. Assimilation of the leaf area index and vegetation temperature condition index for winter wheat yield estimation using Landsat imagery and the CERES-Wheat model. Agric. For. Meteorol. 2017, 246, 194-206. [CrossRef]

32. Mohseni, F.; Mokhtarzade, M. A new soil moisture index driven from an adapted long-term temperature-vegetation scatter plot using MODIS data. J. Hydrol. 2020, 581, 124420. [CrossRef]

33. Swain, S.; Abeysundara, S.; Hayhoe, K.; Stoner, A.M. Future changes in summer MODIS-based enhanced vegetation index for the South-Central United States. Ecol. Inform. 2017, 41, 64-73. [CrossRef]

34. Vijith, H.; Dodge-Wan, D. Applicability of MODIS land cover and Enhanced Vegetation Index (EVI) for the assessment of spatial and temporal changes in strength of vegetation in tropical rainforest region of Borneo. Remote. Sens. Appl. Soc. Environ. 2020, 18, 100311. [CrossRef]

35. Zhang, G.; Xiao, X.; Dong, J.; Kou, W.; Jin, C.; Qin, Y.; Zhou, Y.; Wang, J.; Menarguez, M.A.; Biradar, C. Mapping paddy rice planting areas through time series analysis of MODIS land surface temperature and vegetation index data. ISPRS J. Photogramm. Remote. Sens. 2015, 106, 157-171. [CrossRef]

36. Zhou, X.; Wang, P.; Tansey, K.; Zhang, S.; Li, H.; Wang, L. Developing a fused vegetation temperature condition index for drought monitoring at field scales using Sentinel-2 and MODIS imagery. Comput. Electron. Agric. 2020, 168. [CrossRef]

37. Shrestha, R.; Di, L.; Yu, E.G.; Kang, L.; Shao, Y.-Z.; Bai, Y.-Q. Regression model to estimate flood impact on corn yield using MODIS NDVI and USDA cropland data layer. J. Integr. Agric. 2017, 16, 398-407. [CrossRef]

38. Sotille, M.E.; Bremer, U.F.; Vieira, G.; Velho, L.F.; Petsch, C.; Simões, J.C. Evaluation of UAV and satellite-derived NDVI to map maritime Antarctic vegetation. Appl. Geogr. 2020, 125, 102322. [CrossRef] 
39. Estrany, J.; Ruiz, M.; Calsamiglia, A.; Carriquí, M.; García-Comendador, J.; Nadal, M.; Fortesa, J.; López-Tarazón, J.A.; Medrano, H.; Gago, J. Sediment connectivity linked to vegetation using UAVs: High-resolution imagery for ecosystem management. Sci. Total. Environ. 2019, 671, 1192-1205. [CrossRef]

40. Zhao, F.; Wu, X.; Wang, S. Object-oriented Vegetation Classification Method based on UAV and Satellite Image Fusion. Procedia Comput. Sci. 2020, 174, 609-615. [CrossRef]

41. Li, D.; Wu, S.; Liang, Z.; Li, S. The impacts of urbanization and climate change on urban vegetation dynamics in China. Urban For. Urban Green. 2020, 54, 126764. [CrossRef]

42. Shidiq, I.P.A.; Wibowo, A.; Kusratmoko, E.; Indratmoko, S.; Ardhianto, R.; Nugroho, B.P. Urban forest topographical mapping using UAV LIDAR. IOP Conf. Ser. Earth Environ. Sci. 2017, 98, 012034. [CrossRef]

43. Rumora, L.; Majić, I.; Miler, M.; Medak, D. Spatial video remote sensing for urban vegetation mapping using vegetation indices. Urban Ecosyst. 2021, 24, 21-33. [CrossRef]

44. Gibril, M.B.A.; Kalantar, B.; Al-Ruzouq, R.; Ueda, N.; Saeidi, V.; Shanableh, A.; Mansor, S.; Shafri, H.Z.M. Mapping Heterogeneous Urban Landscapes from the Fusion of Digital Surface Model and Unmanned Aerial Vehicle-Based Images Using Adaptive Multiscale Image Segmentation and Classification. Remote. Sens. 2020, 12, 1081. [CrossRef]

45. Noor, N.M.; Abdullah, A.; Hashim, M. Remote sensing UAV/drones and its applications for urban areas: A review. IOP Conf. Ser.: Earth Environ. Sci. 2018, 169, 012003. [CrossRef]

46. Feng, Q.; Liu, J.; Gong, J. UAV Remote Sensing for Urban Vegetation Mapping Using Random Forest and Texture Analysis. Remote. Sens. 2015, 7, 1074-1094. [CrossRef]

47. Gu, Z.; Zhang, X. Framing social sustainability and justice claims in urban regeneration: A comparative analysis of two cases in Guangzhou. Land Use Policy 2021, 102, 105224. [CrossRef]

48. Hui, E.C.-M.; Chen, T.; Lang, W.; Ou, Y. Urban community regeneration and community vitality revitalization through participatory planning in China. Cities 2021, 110, 103072. [CrossRef]

49. Templeton, L.K.; Neel, M.C.; Groffman, P.M.; Cadenasso, M.L.; Sullivan, J.H. Changes in vegetation structure and composition of urban and rural forest patches in Baltimore from 1998 to 2015. For. Ecol. Manag. 2019, 454, 117665. [CrossRef]

50. Trentanovi, G.; Campagnaro, T.; Kowarik, I.; Munafò, M.; Semenzato, P.; Sitzia, T. Integrating spontaneous urban woodlands into the green infrastructure: Unexploited opportunities for urban regeneration. Land Use Policy 2021, 102, 105221. [CrossRef]

51. Cao, S.; Danielson, B.; Clare, S.; Koenig, S.; Campos-Vargas, C.; Sanchez-Azofeifa, A. Radiometric calibration assessments for UAS-borne multispectral cameras: Laboratory and field protocols. ISPRS J. Photogramm. Remote. Sens. 2019, 149, 132-145. [CrossRef]

52. Morgan, B.; Stocker, M.; Valdes-Abellan, J.; Kim, M.; Pachepsky, Y. Drone-based imaging to assess the microbial water quality in an irrigation pond: A pilot study. Sci. Total. Environ. 2020, 716, 135757. [CrossRef] [PubMed]

53. Praeger, C.; Vucko, M.J.; McKinna, L.; De Nys, R.; Cole, A. Estimating the biomass density of macroalgae in land-based cultivation systems using spectral reflectance imagery. Algal Res. 2020, 50, 102009. [CrossRef]

54. Jiang, R.; Sanchez-Azofeifa, A.; Laakso, K.; Wang, P.; Xu, Y.; Zhou, Z.; Luo, X.; Lan, Y.; Zhao, G.; Chen, X. UAV-based partially sampling system for rapid NDVI mapping in the evaluation of rice nitrogen use efficiency. J. Clean. Prod. 2021, $289,125705$. [CrossRef]

55. Su, J.; Liu, C.; Coombes, M.; Hu, X.; Wang, C.; Xu, X.; Li, Q.; Guo, L.; Chen, W.-H. Wheat yellow rust monitoring by learning from multispectral UAV aerial imagery. Comput. Electron. Agric. 2018, 155, 157-166. [CrossRef] 